\title{
Satisfaction of Patients Treated in Physical Medicine and Rehabilitation Department in CNHU-HKM of Cotonou
}

\section{Hountondji Etienne Alagnide*, Didier Niama Natta, Germain Houngbedji, Mireille Adido, Jean Olouka, Eric Havyarimana, Godonou Toussaint Kpadonou}

Physical Medicine and Rehabilitation Department in CNHU HKM, Cotonou, Benin

Email: *ealagnide@yahoo.fr

How to cite this paper: Alagnide, H.E., Niama Natta, D., Houngbedji, G., Adido, M., Olouka, J., Havyarimana, E. and Kpadonou, G.T. (2018) Satisfaction of Patients Treated in Physical Medicine and Rehabilitation Department in CNHU-HKM of Cotonou. Open Journal of Therapy and Rehabilitation, 6, 8-16.

https://doi.org/10.4236/ojtr.2018.61002

Received: December 26, 2017

Accepted: February 9, 2018

Published: February 12, 2018

Copyright (c) 2018 by authors and Scientific Research Publishing Inc. This work is licensed under the Creative Commons Attribution International License (CC BY 4.0).

http://creativecommons.org/licenses/by/4.0/

\begin{abstract}
Satisfaction of patients is an important dimension of the hospital management and the evaluation of the quality of care and services offered to patients. Objective: To estimate the degree of satisfaction of patients admitted in Physical Medicine and Rehabilitation Department in the National Hospital and University Center (CNHU-HKM) in Cotonou. Method: Cross-sectional study with descriptive and analytical aim. It was led from June 15th to October 15th 2013, on 158 patients or guides of children or not communicating patients having ambulatory care in the Department of Physical Medicine and Rehabilitation and who agree to participate to the study. The level of global satisfaction of the subjects was estimated with a digital scale from 0 to 10 . It was secondarily transformed into a discreet qualitative variable. Result: Rate of participation was $63.2 \%$. Patients had deficiencies of rheumatilogical origine (41.1\%), neurological (27.2\%), traumatological (24.1\%). Their pathologies were evolving since 1 month to 10 years. It was about their first attendance of the Rehabilitation Department of CNHU-HKM in $72.2 \%$. Patients' degree of satisfaction was good for the deadliness of expectation, reception (80\%), cleanliness of the building, respect of patients' intimacy. Global satisfaction of patients was good in $72 \%$. It was influenced by the deadline of evolution of the pathologies. Discussion-Conclusion: The level of satisfaction of patients admitted in the Rehabilitation Department in CNHU-HKM was acceptable. However, they are parameters that remain to be improved.
\end{abstract}

\section{Keywords}

Satisfaction, Hospital Care, Rehabilitation, Cotonou 


\section{Introduction}

Patient satisfaction is an important aspect of hospital management and evaluation of the quality of care and services provided to patients. The concept of assessing patient satisfaction emerged about 1970 in United States, then in England and Northern Europe. Later, the World Health Organization (WHO) included it in the definition of quality of care assessment. Its evaluation enables health care system regulators to be accountable, to increase patients' power of choice and to improve quality of care provided. It also enables patients to describe their point of view on the course of their treatment. Those information will serve to identify different problems that patients have when be treated; and so, solutions will be brought [1]. If patient satisfaction evaluation is almost systematic or even mandatory in developed countries [2] [3], this is not yet the case in our context. In Benin, for example, very few hospital satisfaction surveys were conducted. Born with the reference hospital in Benin in 1962, but with numerous modifications, Physical medicine and Rehabilitation Department (PMRD) of the Hubert K. Maga National Hospital and University Center (CNHU-HKM) take care of patients of all ages and who have different deficiencies and limitations of activities. What satisfaction do these patients have from that department?

\section{Patients and Method of Study}

\subsection{Type of Study and Patients}

It is a cross-sectional study aimed to be descriptive and analytical, covering four months, from June 15th to October 15th 2013.

\subsection{Study Population and Sampling}

Population of this study was made of all patients admitted to the Physical Medicine and Rehabilitation Department of the CNHU-HKM in Cotonou during the study period.

Sampling was conducted taking into account the inclusion and non inclusion criteria listed below.

Inclusion Criteria:

- being a patient or accompanying parent of children or adult patients with impaired comprehension,

- admitted to the PMRD during the study period,

- having performed ambulatory care in the PMRD,

- agreeing by himself to participate to the study.

Exclusion Criteria:

Were excluded from the study, patients:

- having completed less than five re-education sessions,

- hospitalized in another CNHU-HKM department during functional rehabilitation sessions.

Two hundred and fifty (250) patients were enrolled, taking into account these criteria. 


\subsection{Settings}

We have studied a dependent variable and some independent variables. Independent variables were socio-professional category, level of education, existence of social cover, area of patient pathology. For the dependent variable, it was represented by the overall patient satisfaction of the CNHU-HKM Physical Medicine and Rehabilitation Department in Cotonou. For this purpose, on a scale of 0 to 10 , patients gave their appreciation of different parameters of the department (rooms, reception, care...). It was after the evaluation of each of these parameters that the assessment of the patient's overall satisfaction with the department was made, using the same scale from 0 to 10 . From score given by the patient, his level satisfaction was categorized in "No Satisfaction", "Less Satisfaction", "Good Satisfaction" and "Very Good Satisfaction", depending on whether the score was 0 - 4, 4-6,6-8, or 8 - 10, respectively.

Data collection was based on a standardized questionnaire. A direct interview with each patient, before or after a rehabilitation session, was organized. For patients meeting the conditions required to participate to the study, a copy of the questionnaire was provided to them for filling at home, alone or with parents help interpretation. To respect patient anonymity, questionnaire returning was obtained through the secretariat, in a box.

Participation rate was 63.2\%: one hundred and fifty-eight (158) returns of questionnaires.

\subsection{Data Analysis}

Data were entered in Excel version 2007 and their analysis was done using EPI INFO version 3.5.1 software. Frequencies of the different variables were calculated. During the study of factors associated with overall patient satisfaction, a clustering of satisfaction levels was done. For that, the modalities "Less satisfaction" and "No satisfaction" were called "not satisfied" and those "Good satisfaction" and "Very good satisfaction" constituted the group of "satisfied". The statistical analyzes of the tables were done using the chi-square statistical tests and the reduced-deviation tests. Significance threshold was set at $5 \%$.

\section{Results}

\subsection{Patients Characteristics}

Patients were 87 women (55.1\%) and 71 men (44.9\%). Their age ranged from 2 to 74 years, with an average of $42.3 \pm 18.3$ years. It was the first attendance for $77.2 \%$ of patients compared with $22.8 \%$ who have already attended the Physical Medicine and Rehabilitation department of CNHU-HKM at least once. Table 1 presents other characteristics of the patients. It shows that patients were from various socio-professional classes with in top official workers (25.9\%) and traders (20.3\%). They were schooled with a level of at least secondary one for $77.8 \%$. Patients presented various pathologies. The latter were predominantly about rheumatological (41.1\%), neurological (27.2\%) and traumatological ones (24.1\%). 
Table 1. Distribution of patients according to their socio-demographic and clinical characteristics.

\begin{tabular}{|c|c|c|}
\hline & Numbers & Percentages (\%) \\
\hline \multicolumn{3}{|l|}{ Age } \\
\hline Low than 25 years & 43 & 27.2 \\
\hline 25 to 45 years & 36 & 22.8 \\
\hline 45 to 65 years & 62 & 39.2 \\
\hline More than 65 years & 11 & 10.8 \\
\hline \multicolumn{3}{|l|}{ Sex } \\
\hline Male & 71 & 44.9 \\
\hline Female & 87 & 55.1 \\
\hline \multicolumn{3}{|c|}{ Previous Department attendance } \\
\hline Yes & 122 & 77.2 \\
\hline No & 36 & 22.8 \\
\hline \multicolumn{3}{|c|}{ Socio-professional classes } \\
\hline Official workers & 41 & 25.9 \\
\hline Traders/sellers & 32 & 20.3 \\
\hline Learners & 24 & 15.2 \\
\hline Workers & 21 & 13.3 \\
\hline Retirees & 16 & 10.1 \\
\hline Households & 16 & 10.1 \\
\hline Others & 8 & 5.1 \\
\hline \multicolumn{3}{|l|}{ Education levels } \\
\hline None (Unschooled) & 21 & 13.3 \\
\hline Primary & 14 & 8.9 \\
\hline Secondary & 52 & 32.9 \\
\hline University & 71 & 44.9 \\
\hline \multicolumn{3}{|l|}{ Types of pathologies } \\
\hline Rheumatology & 65 & 41.1 \\
\hline Neurology & 43 & 27.2 \\
\hline Traumatology & 38 & 24.1 \\
\hline Uro-gynecology & 9 & 5.7 \\
\hline Pneumology & 3 & 1.9 \\
\hline \multicolumn{3}{|l|}{ Social medical cover } \\
\hline Total at $100 \%$ & 49 & 31.0 \\
\hline Partial at $90 \%$ & 14 & 8.9 \\
\hline Partial at $80 \%$ & 66 & 41.8 \\
\hline None & 29 & 18.3 \\
\hline
\end{tabular}


Those pathologies were evolving between 1 month and 10 years with an average delay of evolution of $8.50 \pm 18.55$ months.

\subsection{Patient Satisfaction}

The mean wait times estimated by patients were $8.2 \pm 5.43$ days for medical examination; $9.45 \pm 15.32$ days for the beginning of rehabilitation sessions and $13.54 \pm 13.85$ minutes for the start of each physiotherapy session. Figure 1 and Figure 2 present results of patient's appreciation of various parameters in order

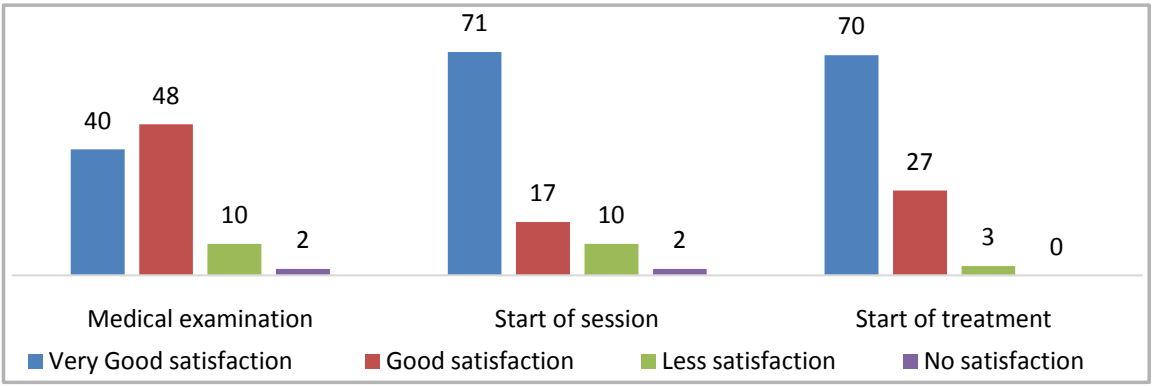

(a)

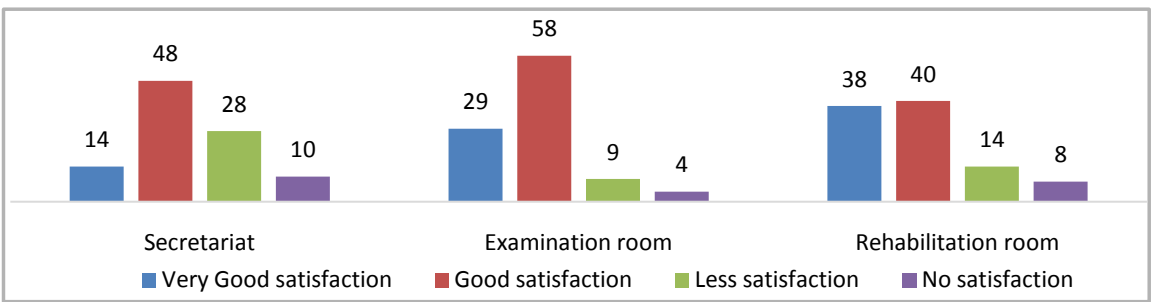

(b)

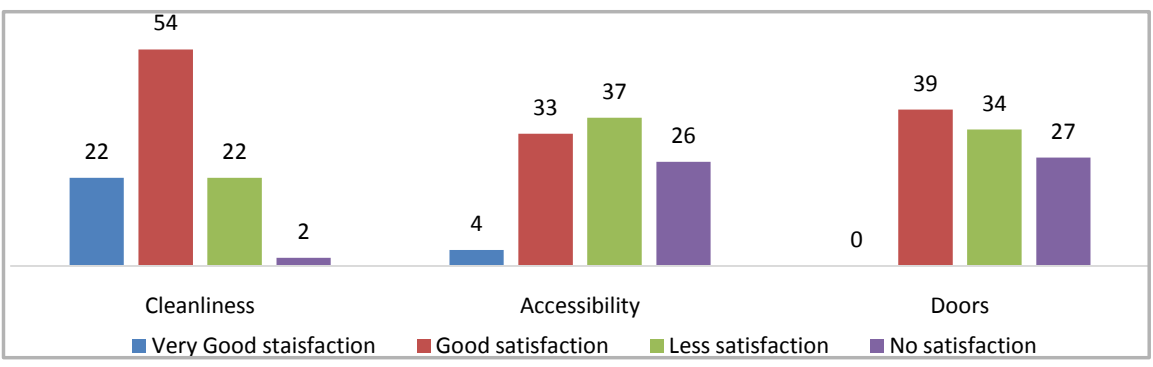

(c)

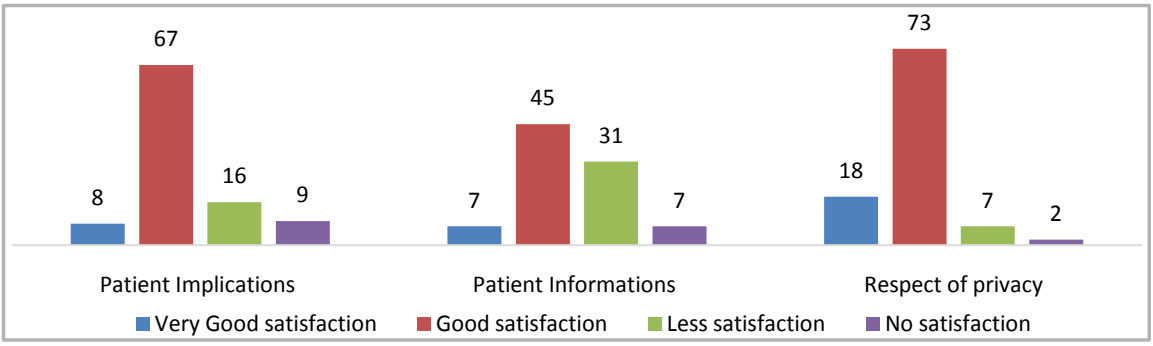

(d)

Figure 1. Distribution of patients according to their level of satisfaction for different parameters (sectory satisfaction). (a) Timeout; (b) Patient reception; (c) Service rooms; (d) Diagnostic and therapeutic procedures. 


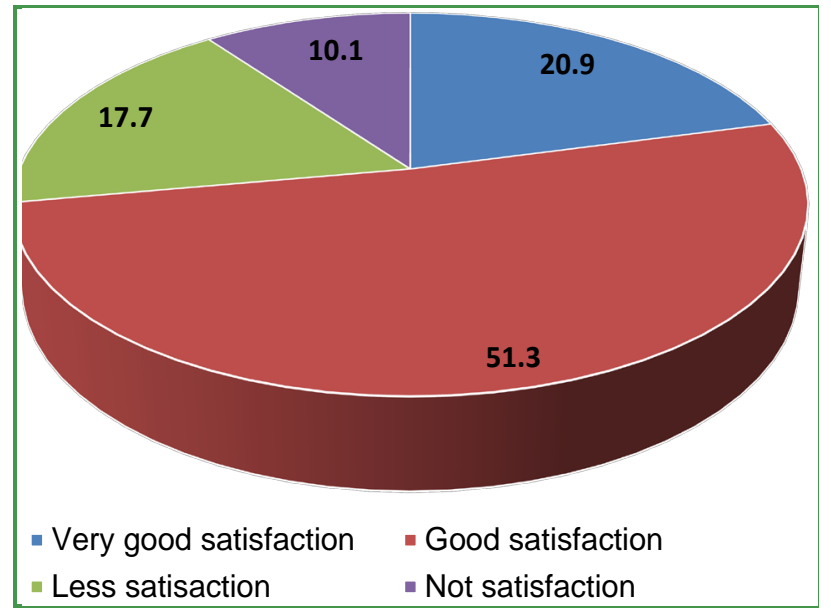

Figure 2. Distribution of patients according to their overall assessment of PMRD satisfaction.

to assess their degree of satisfaction and their overall satisfaction. In general, patients' level satisfaction was at least good (62\% to $97 \%)$. Unsatisfaction was showed specially about information of patient (52\%) and accessibilities in the department (37\%). The study of factors associated with the overall patient's satisfaction is presented in Table 2. Only evolving time of pathologies is linked with patient's satisfaction $(\mathrm{p}=0.01)$.

\section{Discussion}

Patients in the study consisted of $44.9 \%$ of men versus $55.1 \%$ of women, with a sex ratio of 0.82 . These data are comparable to the distribution of the Benin population in general, that is $52 \%$ of women against $48 \%$ of men. Attendance of men and women at the Physical Medicine and Rehabilitation Department of the CNHU-HKM in Cotonou is thus proportional to the distribution of the population of Benin, by sex. From the review of the literature, studies done on patient satisfaction in physical medicine reported varying results. While authors have noted a male predominance [4] [5] [6] [7], others have instead found a female predominance [8] [9].

Patients' age in the sample was 2 to 74 years with an average of $42.3 \pm 18.26$ years. This demonstrates that in the Physical Medicine and Rehabilitation Department of the CNHU-HKM of Cotonou, patients of all ages from infants to elderly are received. This finding was confirmed by other studies carried out in different rehabilitation centers [4] [5] [7] [8] [9] [10] [11].

Regarding their level of education, patients of the study were enrolled in almost all cases, the out-of-school children being mainly children of less than the age of schooling. Almost four out of five patients had at least secondary level. This result can't be superimposed on the distribution of the Beninese population according to the level of schooling, the rate of literacy according to UNESCO being 43.1\% [12]. In Ivry Coast, Alloh et al. [7] reported similar results, with 84\% of patients in their series having at least secondary level. This large disproportion 
Table 2. Factors associated with overall patient satisfaction.

\begin{tabular}{|c|c|c|c|}
\hline & Not satisfied & Satisfied & Statistical test \\
\hline \multicolumn{4}{|l|}{ Sex } \\
\hline Men & 20 & 51 & \multirow{2}{*}{$\begin{aligned} \mathrm{X}^{2} & =0.00 \\
\mathrm{p} & =0.98\end{aligned}$} \\
\hline Women & 24 & 63 & \\
\hline \multicolumn{4}{|l|}{ Previous department attendance } \\
\hline Yes & 11 & 25 & \multirow{2}{*}{$\begin{aligned} \mathrm{X}^{2} & =0.17 \\
\mathrm{p} & =0.68\end{aligned}$} \\
\hline No & 33 & 89 & \\
\hline \multicolumn{4}{|l|}{ Education level } \\
\hline Unschooled & 5 & 16 & \multirow{4}{*}{$\begin{aligned} \mathrm{X}^{2} & =0.42 \\
\mathrm{p} & =0.94\end{aligned}$} \\
\hline Primary & 4 & 10 & \\
\hline Secondary & 16 & 36 & \\
\hline University & 19 & 52 & \\
\hline \multicolumn{4}{|l|}{ Social medical cover } \\
\hline Total & 17 & 32 & \multirow{3}{*}{$\begin{aligned} \mathrm{X}^{2} & =4.08 \\
\mathrm{p} & =0.13\end{aligned}$} \\
\hline Partial & 23 & 57 & \\
\hline None & 4 & 25 & \\
\hline \multicolumn{4}{|l|}{ Types of pathologies } \\
\hline Rheumatology & 16 & 49 & \multirow{4}{*}{$\begin{aligned} \mathrm{X}^{2} & =2.68 \\
\mathrm{p} & =0.44\end{aligned}$} \\
\hline Neurology & 16 & 27 & \\
\hline Traumatology & 9 & 30 & \\
\hline Others & 3 & 9 & \\
\hline Evolving time of the pathology & & & $\mathrm{U}_{\alpha}=2.79$ \\
\hline Mean \pm standard deviation & $4.39 \pm 6.71$ & $9.03 \pm 14.12$ & $\mathrm{p}=0.01$ \\
\hline
\end{tabular}

between the overall enrollment rate and the proportion of patients attending rehabilitation centers in our regions could be explained by the fact that more educated patients are, more informed they are about the availability of different types of treatment of pathologies, therefore physiotherapy.

Figure 1 shows that patients were particularly satisfied with waiting times, their reception in the counseling room and respect for their privacy (89\% to $97 \%)$. About practicability of doors, cleanliness of rooms, reception in the office of secretary and in the rehabilitation room, proportion of patients satisfied were less $(62 \%-80 \%)$. The disappointment was particularly obtained about accessibilities in the department as well as information of patients (37\% to 50\%). These points of dissatisfaction could be related to socio-economic and cultural difficulties. Indeed, while it is well known that environment has a significant place in the definition of disability, financial and technological resources in our countries do not sufficiently allow for this issue of accessibility for people with reduced mobility, to services and public places. As for the non-information of patients, it 
could be justified by the fact that the caregivers do not try to come down to a physical and socio-linguistic level enabling them to really communicate with their patients. This is a particular situation to be deplored given the large part of the communication in the care of patient. According to Casserley et al., in Ireland [11], information being processed was given to patients in $94 \%$ of the cases.

The overall satisfaction level of patients was good in three out of four patients. This result is comparable to that reported by several authors, both in Africa and developed countries [4] [5] [6] [7] [8] [10] [11]. This overall satisfaction rate of patients in our study was not influenced by any of the socio-demographic or clinical factors studied. These are encouraging results which suggest that the staff is benevolent, occupied by a good professional conscience. But it's noticed that patients whose pathologies were involved since a long time were more satisfied than the else.

\section{Conclusion}

In the Physical Medicine and Rehabilitation Department of CNHU-HKM of Cotonou, patients of all ages, various socio-professional categories were taken care of. Overall, they were satisfied with the wait times, the welcome and the care received. But about accessibility to the service and communication with patients, an important part of them are not satisfied. Instead of the limited resources of our African states and the language barriers, it would be interesting for these patients' complaints to be taken into account in order to reduce their disability status, which is the main goal of rehabilitation medicine.

\section{Acknowledgements}

This study could not be possible without participants who consent to let us know their satisfaction about Physical Medical and Rehabilitation Department in CNHU-HKM. We sincerely acknowledge all participants to this study.

\section{Conflicts of Interest}

Authors declared they have no conflict of interest.

\section{References}

[1] Pourin, C., Barberger-Gateau, P., Michel, P. and Salamon, R. (1999) Inpatient Satisfaction Measurement: Conceptual Aspects and Review of the Work. Journal of Medical Economics, 17, 101-115.

[2] Young, G.J., Meterko, M. and Desai, K.R. (2000) Patient Satisfaction with Hospital Care: Effects of Demographic and Institutional Characteristic. Medical Care, 38, 325-334. https://doi.org/10.1097/00005650-200003000-00009

[3] Jeune, G.J., Meterko, M. and Desai, K.R. (2000) Satisfaction des Patients aux Soins Hospitaliers: Effets des Caractéristiques Démographiques et Institutionnelles de Soins. Medical Care, 38, 325-334.

[4] Beattie, P.F., Pinto, M.B., Nelson, M.K. and Nelson, R.M. (2002) Patient Satisfaction without Patient Physical Therapy: Instrument Validation. Physical Therapy, 82, 
557-565.

[5] Knight, P., Cheng, A.N. and Lee, G.M. (2010) Results of a Survey of Client Satisfaction without Patient Physiotherapy Care. Physiotherapy Theory and Practice, 26, 297-307. https://doi.org/10.3109/09593980903164058

[6] Hills, R. and Kitchen, S. (2007) Development of a Model of Patient Satisfaction with Physiotherapy. Physiotherapy Theory and Practice, 23, 255-271. https://doi.org/10.1080/09593980701249929

[7] Alloh, D., Aka, N., Manou, B., Bombo, J., Kouakou, J. and Pillah, L. (2011) Evaluation de la Satisfaction des Patients d'Hospitalisation de Jour de Rééducation à Abidjan. Médecine d'Afrique Noire, 5802, 63-68.

[8] Goldstein, M.S., Elliott, S.D. and Guccione, A.A. (2000) The Development of an Instrument to Measure Satisfaction with Physical Therapy. Physical Therapy, 80, 853-863.

[9] McCracken, L.M., Klock, P.A., Mingay, D.J., Asbury, J.K. and Sinclair, D.M. (1997) Assessment of Satisfaction with Treatment for Chronic Pain. Journal of Pain and Symptom Management, 14, 292-299. https://doi.org/10.1016/S0885-3924(97)00225-X

[10] Monnin, D. and Perneger, T.V. (2002) Scale to Measure Patient Satisfaction with Physical Therapy. Physical Therapy, 82, 682-691.

[11] Casserley-Feeney, S.N., Phelan, M., Duffy, F. et al. (2008) Patient Satisfaction with Private Physiotherapy for Musculoskeletal Pain. BMC Musculoskeletal Disorders, 9 , 50. https://doi.org/10.1186/1471-2474-9-50

[12] United Nations for Educational, Scientific and Cultural Organization (2015) Education for All Benin. 1-4. 